\title{
Incidence and presentation of myocardial infarction in an English community
}

\author{
L. J. Kinlen ${ }^{1}$ \\ From the Department of the Regius Professor of Medicine, Radcliffe Infirmary, Oxford
}

An attempt was made to determine the incidence and presentation of myocardial infarction in a community of 375,000 in the Oxford area. Through local general practitioners and hospital records supplemented by the Oxford Record Linkage Study and certificates of sickness incapacity, 357 patients aged under 70 were found and divided into four categories according to the extent and type of diagnostic support. All patients or, if dead, their relatives were interviewed soon after the attack.

The incidence of myocardial infarction in the Oxford area was appreciably lower than that found by similar methods in Edinburgh, confirming the difference implied by mortality rates in these two areas. The mortality pattern was distinctive, the likelihood of death being highest in the first few hours and quickly declining to much lower levels. This pattern was reflected in the high proportion of fatal attacks which were medically unattended (65\%), outside hospital (63\%), or unwitnessed and discovered after an appreciable delay (24\%). Consequently, the clinician in hospital has a very limited view of myocardial infarction.

Epidemiological surveys have been used widely to study the aetiology of ischaemic heart disease, but few attempts have been made to assess the incidence of myocardial infarction in a whole community. Most clinical studies of this condition have been carried out in hospital and take no account of cases managed at home or those presenting as sudden and unexpected death outside hospital. Only a study based on a whole population will include all these groups and permit an examination of those factors that determine which cases reach hospital. It is only with this knowledge that the value of hospital treatment of myocardial infarction can be assessed. This approach is also relevant to the organization and extension of resuscitation services.

\section{Method}

With these aims in mind, a study of the incidence and presentation of myocardial infarction was undertaken in the Oxford area in 1966-1967. The study area comprised the North Berkshire municipal boroughs of Abingdon, Wantage, and Wallingford, together with their associated rural districts, and Oxfordshire except for Henley and Banbury and their rural districts. This area covered 785 square miles and involved a population of about 375,000 people under the age of 70 .

Received I5 December 1972.

${ }^{1}$ Formerly of the Oxford Record Linkage Study and the Nuffield Department of Clinical Medicine, Oxford.
Notification and ascertainment An attempt was made to ascertain every diagnosed case of myocardial infarction in persons under the age of 70 in the above area. Cases were ascertained in one or more of the following ways.

i) General practitioners All but one of the 136 general practitioners practising in the area agreed to notify any case of probable myocardial infarction, including sudden death, in their patients under 70 years of age. Cases were notified mainly by telephone and an automatic answering device was used outside office hours. Co-operation was encouraged by a fee of 5op, which was paid in each case irrespective of the final diagnosis. Regular progress reports were sent to the doctors co-operating in the study.

ii) Hospital admissions Only one general hospital in the area, the Radcliffe Infirmary, normally accepts patients for emergency medical care and all admissions to this hospital were screened daily for possible cases of myocardial infarction. Contact was also maintained with cottage hospitals in the area so that the few cases admitted there would not be missed.

iii) Other medical practitioners All the consultant physicians in the area agreed to notify cases seen in private or domiciliary practice and industrial medical officers also co-operated.

iv) Death certificates As the area covered by the survey was within the catchment area of the Oxford Record Linkage Study (Acheson, 1964), it was possible to 
examine death certificates in respect of all deaths occurring during the period.

v) Coroners' cases The coroners and the forensic pathologists in the area co-operated and copies of all relevant postmortem reports were received routinely.

vi) Other necropsies The reports of all hospital necropsies in the area were examined regularly.

vii) Electrocardiograms All electrocardiograms recorded in the Radcliffe Infirmary, together with the small number taken by general practitioners and sent there for reporting, were examined to try to pick up additional cases.

viii) Serum enzyme estimations All requests for serum transaminase estimations were screened in the biochemistry department of the Radcliffe Infirmary, which also provides a service for the surrounding area.

ix) Certificates of incapacity The Ministry of Social Security screened first certificates of incapacity for diagnoses suggestive of myocardial infarction.

The fact that many cases were found independently from several different sources provided a measure of the co-operation of the participants. Only one case not already ascertained from another source was uncovered by the screening of certificates of incapacity.

Procedure Patients found by one or more of the above methods who were still living and who satisfied the diagnostic criteria were interviewed. A standard form was completed incorporating identifying details, diagnostic data, and details both of previous health and of the recent episode, including the timing of various events. Patients treated at home by their general practitioners were visited within a short time of notification, an electrocardiogram was recorded, and a blood specimen collected for enzyme estimations. In cases of death, permission was sought from the general practitioner concerned to approach the relatives for information.

Diagnostic criteria The electrocardiographic criteria for the diagnosis of recent myocardial infarction were taken from World Health Organization (1959). Unfortunately, however, these criteria were designed for screening populations for evidence of previous infarction, both recent and of long standing, and were found to have several shortcomings in the present context. Thus, for example, no opportunity was allowed for associated enzyme changes to influence the diagnosis. Even with the provision for raised enzyme levels, these electrocardiographic patterns were quickly found to be too rigid and the descriptions somewhat ambiguous. An additional electrocardiographic category was therefore formulated to include bundle-branch block or certain patterns consistent with subendocardial infarction, provided the clinical picture and the serum enzyme level supported the diagnosis. A group studying the incidence of myocardial infarction in Edinburgh encountered the same difficulties and added a similar category to their criteria (A. Armstrong, 1967, personal communication). Cases were accepted if they fell into one of the following categories which differ in the degree of ante- or postmortem support.

I) Any case with raised serum enzyme levels (as defined below) and any of the electrocardiographic abnormalities (a)-(o) described by the World Health Organization (1959); any case with raised enzyme levels and an electrocardiogram showing $\mathrm{T}$ wave inversion in leads I or aVL, bundle-branch block, or ST depression. Only cases with serial electrocardiographic abnormalities of an injury current pattern were acceptable in the absence of enzyme changes.

2) Any case with a recent coronary thrombosis or recent myocardial necrosis found at necropsy, if not included in the previous category.

3) Any case not included in the first category in which death was sudden and a necropsy showed only longstanding changes of coronary disease (coronary atheroma or myocardial fibrosis) but no other cause for death.

4) Any case not included in the first category in which death was sudden and attributed (without a necropsy) to ischaemic heart disease.

Cases in the last three categories are by definition fatal, but only a proportion in the first group was fatal. All patients in the first group were seen by a doctor but within the other categories (2-4) a distinction was made between medically attended and unattended deaths, the latter being defined as cases where the patient was not seen by a doctor during life after the onset of the attack.

All electrocardiograms from patients notified to the study or admitted to hospital with suspected myocardial infarction were classified independently by two observers. Where there was disagreement a third observer arbitrated but only 7 cases gained admission to the study as a result of his casting vote.

Serum enzyme levels The following were regarded as raised: a serum aspartate aminotransferase level of over 40 Sigma Frankel units per ml, a lactic dehydrogenase level of over $225 \mathrm{mIU}$ per $\mathrm{ml}$ (by the WroblewskiLa Due method), or a hydroxybutyric dehydrogenase level of over $125 \mathrm{mIU}$ per $\mathrm{ml}$ (by the modified Wroblewski-La Due method).

\section{Results}

Table I shows for each sex separately and for both sexes together the numbers of patients ascertained who experienced at least one attack of myocardial infarction. Cases have been separated into four categories according to the evidence on which the diagnosis was based. A full medical history and clinical examination, together with electrocardiogram and serum enzyme support, were obtained for 201 episodes of myocardial infarction experienced by 194 of the 222 patients who were seen by a doctor at least once in the attack. 
TABLE I Number of persons (attended and unattended) with myocardial infarction, by sex and type of diagnostic support

\begin{tabular}{|c|c|c|c|c|c|c|c|}
\hline \multirow[t]{2}{*}{ Type of evidence } & \multicolumn{2}{|c|}{ Attended cases } & \multicolumn{2}{|c|}{ Unattended cases } & \multicolumn{3}{|c|}{ Total } \\
\hline & $M$ & $F$ & $M$ & $F$ & $M$ & $F$ & Both sexes \\
\hline \multirow{4}{*}{$\begin{array}{l}\text { I) With electrocardiographic and enzyme support } \\
\text { 2) Without electrocardiographic and enzyme support: } \\
\text { 2a) Recent thrombosis or infarction found at necropsy } \\
\text { 2b) Long-standing changes only found at necropsy } \\
\text { 2c) Certified without necropsy }\end{array}$} & I4I & 37 & $\circ$ & 0 & I4I & 37 & 178 \\
\hline & 12 & 3 & 53 & 9 & 65 & 12 & 77 \\
\hline & 4 & 0 & 25 & 6 & 29 & 6 & 35 \\
\hline & 20 & 7 & 33 & 12 & 53 & 19 & 72 \\
\hline Total & 177 & 47 & I I I & 27 & 288 & 74 & 362 \\
\hline
\end{tabular}

Presentation of myocardial infarction This is split into those cases who were attended and those who were not.

Attended cases The principal symptoms described by 194 patients in 201 confirmed attacks of myocardial infarction are shown in Table 2. This information was elicited at a standard interview. In four-fifths of the episodes chest or epigastric pain (usually lasting for more than half an hour) was the predominant feature. In two-thirds of the episodes the pain radiated to one or more of the following sites: neck, jaw, arms, and fingers. Pain sometimes occurred in unusual sites. For example, in two instances the pain began in the back of the neck and occipital region, while in three others pain radiated there from the chest. In 16 cases $(8 \%)$ there was radiation to the back.

Only one-fifth of patients described their chest pain as crushing, constricting, or vice-like, and, indeed, burning was a more frequently used adjective. More often, however, the pain was reported as being 'like indigestion' and antacids were often taken before calling a doctor, even by some patients with a previous history of proven peptic ulceration or by others with a previous myocardial infarction. The feeling was often stressed that if only eructation were possible the discomfort would be relieved. Others reported the wish that they could 'open their chests' to relieve the intense feeling of pressure which seemed to be exerted outwards from within

TABLE 2 Predominant symptom in attended cases of acute myocardial infarction

\begin{tabular}{lrr}
\hline Symptom & No. & \multicolumn{1}{c}{$\%$} \\
\hline Pain in chest or epigastrium & 176 & $8 \mathrm{r} \cdot 6$ \\
Dyspnoea & 7 & $3 \cdot 5$ \\
Syncope or collapse & 16 & $8 \cdot 0$ \\
Other symptoms & 2 & $1 \cdot 0$ \\
\hline Total episodes in 194 patients & 201 & \\
\hline
\end{tabular}

and not from outside the chest. Symptoms such as nausea, flatulence, vomiting, and diarrhoea were present in more than half the cases and encouraged the hope or belief that the pain was alimentary in origin. Sweating was reported in 63 per cent of cases and fear admitted in 33 per cent. Yawning and hiccups were occasionally mentioned.

Occasionally pain referred to the arms was partially relieved by allowing the arms to hang loosely, or in other cases by pulling with both hands on a fixed object. Several patients gained some relief by resting on their hands and knees.

In 69 per cent of the episodes, the attack began at home, in 8 per cent at work, in I4 per cent out of doors, and 9 per cent in hospital. Of those in hospital, about half followed an admission on account of suspected myocardial infarction or because of increasing angina. Physical exertion is difficult to quantify in a study of this sort, but it is noteworthy that only 4 of the 194 patients were engaged in heavy exertion immediately before or at the time of the attack. Only one attack began during sexual intercourse and one during the performance of an exercise tolerance test.

Medically unattended cases There were 140 patients who died before being seen by a doctor after the onset of the attack, of whom 5 had experienced a proven myocardial infarction more than one month previously during the study period. Of the deaths in these medically unattended cases, 60 per cent were witnessed, in 15 per cent the deceased was found within minutes of death, while in 25 per cent of cases the body was found after an appreciable delay ranging from one hour to three days. The places of occurrence of these sudden deaths were strikingly similar to the location of patients at the onset of attended cases of myocardial infarction referred to above, and 64 per cent occurred at home, I I per cent at work, 15 per cent out of doors, and 9 per cent in hospital. Thirty per cent of these deaths occurred while the patient was in bed. Three men 
died during or immediately after sexual intercourse, while one patient died driving a car.

Information about symptoms preceding death in these cases was necessarily indirect and was mainly obtained from relatives. In most cases where the patient was accompanied there was evidence of chest or epigastric pain within a few hours of death, though sometimes this was only indicated by the patient holding his chest.

Prodromal symptoms of myocardial infarction Table 3 shows that in both attended and unattended cases, chest or epigastric pain occurred in the previous month in more than half of all cases. The frequency of premonitory pain in the unattended group is probably an underestimate due to the source of the data. In 49 per cent of attended cases and 33 per cent of unattended sudden deaths, the pain either began in the previous month or changed significantly in severity or frequency in this period.

It was common for wives of men who had died suddenly to describe spontaneously an increase in tiredness or progressive loss of energy in the weeks or months before death. This applied to $4 \mathrm{I}$ per cent of such cases (Table 3 ) while in over 20 per cent a recent change in appearance was noted. This was variously described as looking older, drawn, pinched, grey, or pale.

Characteristics of patients with myocardial infarction In about 17 per cent of cases both of attended proven myocardial infarction and unattended sudden deaths, there was a previous history of proven myocardial infarction. The frequency of a diagnosis of previous angina and high blood pressure reported by the patient is shown in Table 4. A diagnosis of angina was accepted if made by a doctor or if chest pain was characteristically related to exertion and relieved by rest.

TABLE 3 Symptoms in month before myocardial infarction or unattended death

\begin{tabular}{|c|c|c|c|c|}
\hline & \multicolumn{2}{|c|}{$\begin{array}{l}\text { Myocardial } \\
\text { infarction }\end{array}$} & \multicolumn{2}{|c|}{$\begin{array}{l}\text { Unattended } \\
\text { death }\end{array}$} \\
\hline & No. & $\%$ & No. & $\%$ \\
\hline $\begin{array}{l}\text { Onset of pain } \\
\text { Significant change in }\end{array}$ & 46 & $23 \cdot 7$ & 26 & $18 \cdot 6$ \\
\hline previous pain & 49 & $25 \cdot 3$ & 20 & $14 \cdot 3$ \\
\hline Previous pain unchanged & 33 & $17 \cdot 0$ & 32 & $22 \cdot 9$ \\
\hline No pain & 51 & $26 \cdot 3$ & 44 & $31 \cdot 4$ \\
\hline Tiredness & 38 & 19.6 & 57 & $40 \cdot 7$ \\
\hline Dyspnoea & 37 & $19 \cdot 1$ & 30 & $21 \cdot 4$ \\
\hline Change in appearance & 5 & $2 \cdot 6$ & 30 & $21 \cdot 4$ \\
\hline Total patients & 194 & & 140 & \\
\hline
\end{tabular}

TABLE 4 Frequency of known coronary heart disease and 'high blood pressure' in patients with myocardial infarction and unattended death

\begin{tabular}{lcclll}
\hline & \multicolumn{2}{l}{$\begin{array}{l}\text { Myocardial } \\
\text { infarction }\end{array}$} & & \multicolumn{2}{l}{$\begin{array}{l}\text { Unattended } \\
\text { death }\end{array}$} \\
\cline { 2 - 3 } \cline { 6 - 7 } \cline { 5 - 6 } & No. & $\%$ & & No. & $\%$ \\
\hline Angina & 85 & $43 \cdot 8$ & & 45 & $32 \cdot 1$ \\
$\begin{array}{l}\text { Definite or probable } \\
\text { myocardial infarction }\end{array}$ & 37 & $19 \cdot 1$ & & 28 & $20 \cdot 0$ \\
High blood pressure & 59 & $30 \cdot 4$ & & 35 & $25 \cdot 0$ \\
\hline Total patients & 194 & & & 140 & \\
\hline
\end{tabular}

Of the 194 attended patients with proven myocardial infarction, $6(3 \%)$ gave a history of gout, 10 $(5 \%)$ of diabetes, while $3(\mathrm{I} \cdot 5 \%)$ had proven hypercholesterolaemia under treatment. Of unattended sudden deaths, I5 (8\%) had diabetes and I patient had known hypercholesterolaemia. Of the women in the study, three-quarters had not menstruated for Io years or more, and only 3 women had had a menstrual period within 2 months of the attack. In 6 cases, menstruation had ceased as a result of hysterectomy.

Incidence Table 5 shows the number of cases of myocardial infarction in men by age and type of case as ascertained during the 9 months of the study, together with the estimated total annual incidence rates. The corresponding data for women are given in Table 6. It will be noted that only in about half of all cases was the diagnosis confirmed during life by electrocardiographic and serum enzyme changes. Among the remaining (all fatal) cases, the diagnosis was often unsupported by any specific findings since necropsy was either not performed or showed no recent myocardial necrosis or coronary thrombosis. In such cases the diagnosis was based on a history of chest pain or the manner of death, in the absence of other evident cause. The validity of this practice is discussed later in this paper. Incidence increased considerably with age and was appreciably greater in men than in women.

Mortality pattern in myocardial infarction It can be seen from Table $I$ that the confirmation by electrocardiogram or enzyme changes in only half of the cases of myocardial infarction is largely due to the large proportion of deaths $(64.8 \%)$ which occurred before a doctor reached the patient. Obviously, these investigations are only possible in living patients. What determines whether a patient with acute myocardial infarction is seen by a doctor during life ? Two relevant factors are the promptness 
TABLE 5 Number of cases and incidence of myocardial infarction, by age, in the Oxford area: men

\begin{tabular}{|c|c|c|c|c|c|c|}
\hline \multirow[t]{2}{*}{ Age } & \multicolumn{2}{|l|}{ Confirmed } & \multicolumn{2}{|l|}{ Presumed } & \multirow[t]{2}{*}{ Total } & \multirow{2}{*}{$\begin{array}{l}\text { (rate per } 1000 \\
\text { per year) }\end{array}$} \\
\hline & $\begin{array}{l}\text { Electrocardiogram } \\
\text { and enzymes }\end{array}$ & Necropsy & $\begin{array}{l}\text { Only long-standing coronary } \\
\text { disease found at necropsy }\end{array}$ & $\begin{array}{l}\text { Other deaths } \\
\text { (no necropsy) }\end{array}$ & & \\
\hline $\begin{array}{l}30-39 \\
40-49 \\
50-59 \\
60-69\end{array}$ & $\begin{array}{r}5 \\
24 \\
58 \\
54\end{array}$ & $\begin{array}{r}2 \\
13 \\
19 \\
31\end{array}$ & $\begin{array}{r}1 \\
5 \\
9 \\
14 \\
\end{array}$ & $\begin{array}{r}0 \\
5 \\
13 \\
35\end{array}$ & $\begin{array}{r}8 \\
47 \\
99 \\
134\end{array}$ & $\begin{array}{r}(0.4) \\
(2.7) \\
(5.7) \\
(13.0)\end{array}$ \\
\hline Total & I4I & 65 & 29 & 53 & 288 & $(4 \cdot 5)$ \\
\hline
\end{tabular}

TABLE 6 Number of cases and incidence of myocardial infarction, by age, in the Oxford area: women

\begin{tabular}{|c|c|c|c|c|c|c|}
\hline \multirow{2}{*}{ Age } & \multicolumn{2}{|l|}{ Confirmed } & \multicolumn{2}{|l|}{ Presumed } & \multirow[t]{2}{*}{ Total } & \multirow{2}{*}{$\begin{array}{l}\text { (rate per } 1000 \\
\text { per year) }\end{array}$} \\
\hline & $\begin{array}{l}\text { Electrocardiogram } \\
\text { and enzymes }\end{array}$ & Necropsy & $\begin{array}{l}\text { Only long-standing coronary } \\
\text { disease found at necropsy }\end{array}$ & $\begin{array}{l}\text { Other deaths } \\
\text { (no necropsy) }\end{array}$ & & \\
\hline $30-39$ & 0 & 0 & 0 & 0 & 0 & 0 \\
\hline $40-49$ & 4 & I & 0 & 0 & 5 & $(0.2)$ \\
\hline $50-59$ & 9 & 4 & 3 & 2 & 18 & $(I \cdot 0)$ \\
\hline $60-69$ & 24 & 7 & 3 & 17 & $5 I$ & $(3 \cdot 9)$ \\
\hline Total & 37 & 12 & 6 & 19 & 74 & $(\mathbf{I} \cdot \mathbf{I})$ \\
\hline
\end{tabular}

of patients in seeking medical help and that of doctors and other medical services in responding. The most important factor, however, is the frequent supervention of death soon after the apparent onset of the attack, as shown in the Fig. This shows the percentage distribution of patients who died within one month of the attack at various intervals after the onset of symptoms, though an important qualification needs to be made in this connexion. In the cases where death occurred before a doctor could attempt to determine the time of onset of symptoms, the approximate hour of onset could only be inferred from the highly variable testimony of relatives. If the onset in unattended cases of sudden death is taken to be the time these patients first reported troublesome symptoms in the 12 hours before their collapse, half of all deaths in the first month occurred within an hour of the onset (curve A). Curve B shows the distribution of deaths when the onset is defined as the time of collapse or when incapacitating symptoms developed, according to which 64 per cent of all deaths occurred in the first hour. The onset in unattended fatal attacks was taken (as in the surviving attended cases) as being the time those symptoms began which prompted the call to the doctor. The distribution of these cases is shown in curve $\mathrm{C}$.

\section{Discussion}

Incidence This study represented the first attempt to assess the overall incidence of myocardial infarc- tion (including unattended deaths) in a whole community in which the diagnosis in home treated cases was placed on a firm basis comparable with that more usually applied in hospital. Shortly after it was begun, a somewhat similar project was mounted in Edinburgh though not all general practices in the city participated in the comprehensive part of the study (Armstrong et al., 1972). Before the Ox-

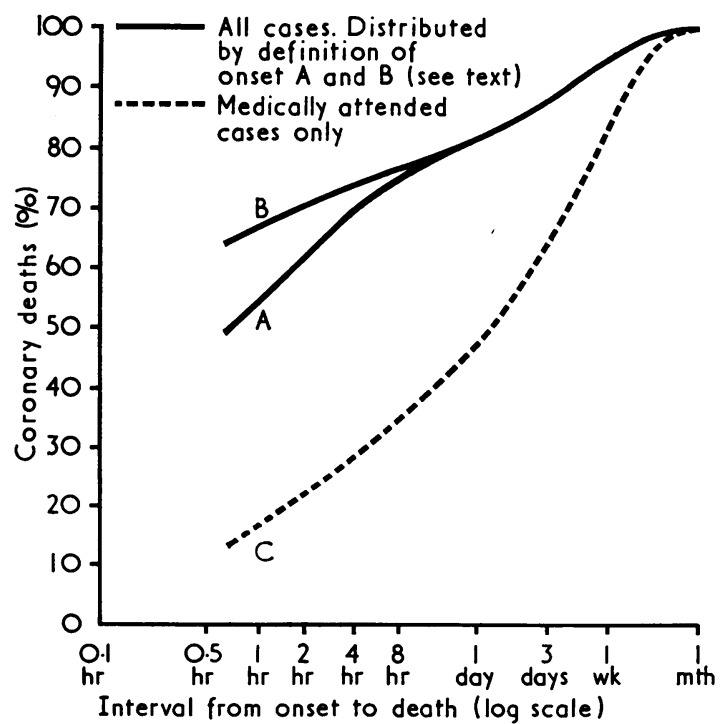

FIGURE 
ford study, only 4 total incidence studies in the general population had been reported, 3 in Scandinavia - in Malmo, Sweden (Björck, Blomqvist, and Sievers, 1959; Sievers, 1963), in Oslo (Westlund and Hougen, 1956, 1961), and in Denmark (Mosbech and Dreyer, 1966), while a fourth was in North Dakota, U.S.A. (Painter et al., 1960). However, these differed in design and diagnostic criteria from the present study. Thus the Scandinavian studies did not include home-treated cases (unless fatal), the diagnostic criteria in the Danish study (which covered only the months March and April, 1963) were not standardized, and the Swedish study took no account of serum enzyme changes. Cases in the latter study with possibly long-standing electrocardiographic abnormalities accompanied by 'unusually severe anginal pain' were accepted. Similarly, the Oslo survey included cases with the residual changes of old infarction if these were first noted during the study period. The Dakota study was carried out in a relatively small population using diagnostic criteria which included coronary insufficiency. A five-year incidence study by McWhinney (1968) in a group practice in Stratfordupon-Avon was limited by the population being small $(8000)$ and representing only part of that town.

Unlike large-scale prospective studies such as that in Framingham, incidence studies of the present type provide no information on aetiology but give data which may be helpful for the planning of medical services. In addition, if carried out in different parts of the country, studies of this sort may confirm or refute the suggestion provided by death rates that there may be interregional variation in the incidence or fatality of the disease. Thus death rates for arteriosclerotic heart disease in Oxford are among the lowest in the United Kingdom (RegistrarGeneral, 1970), whereas the rate in Scotland is much higher. Though in theory this difference could be explained by a higher fatality rate in Scotland, the present results suggest that it may be due at least in part to a higher incidence in that country. The annual incidence of myocardial infarction in the Oxford area was 4.5 per 1000 men aged under 70 in contrast with a figure of 8.4 found by similar methods in Edinburgh (Armstrong et al., 1972; B. Duncan, 1972, personal communication).

Diagnostic criteria It is clear that the more restricted the diagnostic criteria, the lower will be the estimated incidence rate, and vice versa. One of the distinctive features of myocardial infarction is that it may present with death, or at least cause death so quickly that there is no time to substantiate the diagnosis during life. Adherence exclusively to antemortem criteria would exclude this important and considerable group of cases. Even the inclusion of all cases proven at necropsy, however, still leaves a substantial group of cases in which necropsy was not performed or in which no evidence of thrombosis or infarction was found at necropsy. These negative findings raise a more basic problem. Absence of myocardial necrosis may be due to the supervention of a fatal arrhythmia before the macroscopical changes of infarction have developed, which may take up to 3 days (Mallory, White, and Salcedo-Salgar, 1939; Lodge-Patch, 195I); failure to find a recent thrombosis may simply be due to the limited nature of the search. When neither a thrombosis nor muscle necrosis is found, however, the justification for attributing death to an unobserved arrhythmia precipitated by an undetected thrombosis cannot be taken for granted. Coronary atheroma is an expected finding in adults in Western society, while myocardial fibrosis is not uncommon. Moreover, in some reported cases of sudden death attributed to myocardial ischaemia, the cardiac findings may be indistinguishable from those found in cases of accidental death (Mason, 1963; Rigal, Lovell, and Townsend, 1960). In this study there were 35 cases of this type, all of which were attributed by coroners' pathologists to myocardial ischaemia, which until recently was allocated to the same code $(420 \cdot \mathrm{I})$ as frank myocardial infarction. In this group the mean cardiac weight, the degree of myocardial fibrosis, and the frequency of angina and hypertension were not significantly different from proven cases, suggesting that this certification practice is on the whole correct. Nevertheless, in any individual case the diagnosis is unproven and may be wrong.

Identification of onset The definition of the onset is relevant to any discussion of prodromal symptoms, since what is regarded as the onset will necessarily demarcate the premonitory symptoms from those of the attack itself. In this study the onset was regarded in interviewed cases as the time those symptoms began which prompted the patient to seek help. In some cases a later sudden increase in the chest pain or a similar pain the previous day might with equal validity be considered as the onset even though the patient had not called a doctor. There is, however, no accurate means of determining the time of onset in myocardial infarction, or indeed any means of establishing the precise relation between pathology and symptoms. Investigations provide little help in this matter and even the shape of the curve of serial enzyme estimations cannot be used reliably to identify the time when the infarct 
occurred (Whitby, 1968). Similarly, electrocardiograms may be normal in the early stages, even just before a cardiac arrest (Lawrie et al., 1968). Necropsies are even more unsatisfactory and conventional techniques may be unable to demonstrate any recent change. Moreover, more refined studies are greatly affected by the interval between death and fixing the tissue. The difficulties in defining the onset were among the reasons which made Lown (1968) reluctant to give data on the intervals between onset and admission to his unit. In spite of this uncertainty, there is no doubt that the early mortality of myocardial infarction in relation to the onset of symptoms is considerable.

Prodromal symptoms Premonitory chest pains are well known before many attacks of myocardial infarction and were frequent in the present series. Their predictive value, however, is difficult to evaluate because they often only come to notice when reported by patients later presenting with established infarcts. Consequently there is no means of knowing the prevalence of symptoms of this sort which are not followed by infarction.

Still more difficult to evaluate is the tiredness reported by relatives in the weeks or months before death in 40 per cent of sudden and unexpected deaths. It is possible that the judgment of these observers would often be clouded by their recent bereavement. Nevertheless, the extent of the tiredness described, sometimes causing the person to fall asleep at meals, could be striking. Oliver (I966) has reported that abnormal tiredness quite often precedes the development of overt features of ischaemic heart disease, but most of the standard textbooks on cardiology make no mention of this symptom.

I am indebted to Professor E. D. Acheson, who suggested and supervised the study and was also most helpful in his criticism of this manuscript. I am also very grateful to many others in the Oxford area who made this study possible: the general practitioners, physicians, pathologists, medical officers of health, and industrial medical officers; the chief ambulance officers of the area, the biochemistry department of the Radcliffe Infirmary, the staff of the Oxford Record Linkage Study, and to Dr. P. Dandona who reviewed all the electrocardiograms. The work was carried out in the Oxford Record Linkage Study and the Nuffield Department of Clinical Medicine with financial support from the Department of Health and Social Security and the Nuffield Provincial Hospitals Trust.

\section{References}

Acheson, E. D. (1964). The Oxford record linkage study. British fournal of Preventive and Social Medicine, 18, 8.

Armstrong, A., Duncan, B., Oliver, M. F., Julian, D. G., Donald, K. W., Fulton, M., Lutz, W., and Morrison, S. L. (1972). Natural history of acute coronary heart attacks. A community study. British Heart fournal, 34, 67.

Björck, G., Blomqvist, G., and Sievers, J. (1959). Studies on myocardial infarction in Malmö I935 to I954: IV. Myocardial infarcts in the hospital in relation to coronary heart disease in the population. Acta Medica Scandinavica, 165, I.

Lawrie, D. M., Higgins, M. R., Godman, M. J., Oliver, M. F., Julian, D. G., and Donald, K. W. (1968). Ventricular fibrillation complicating acute myocardial infarction. Lancet, 2, 523.

Lodge-Patch, I. (195I). The ageing of cardiac infarcts, and its influence on cardiac rupture. British Heart fournal, 13, 37.

Lown, B. (1968). Coronary care units: current policies and results. In Acute Myocardial Infarction, p. 20. Ed. by D. G. Julian and M. F. Oliver. Livingstone, Edinburgh.

Mason, J. K. (1963). Asymptomatic disease of coronary arteries in young men. British Medical fournal, 2, 1234.

McWhinney, I. R. (1968). Incidence of ischaemic heartdisease in a county-town group practice. Lancet, 2, 342.

Mallory, G. K., White, P. D., and Salcedo-Salgar, J. (I939). The speed of healing of myocardial infarction. American Heart fournal, 18, 647.

Mosbech, J., and Dreyer, K. (1966). Coronary occlusion in Denmark: morbidity and mortality. Acta Medica Scandinavica, 180, 429.

Oliver, M. F. (1966). Presymptomatic diagnosis of precocious ischaemic heart disease. Symposium of 5 th World Congress of Cardiology, p. 377. Acta Cardiologica, Brussels.

Painter, R. C., Ralston, L. S., Fawcett, R. M., Zukel, W. J., and Lewis, R. H. (1960). Short-term study of coronary heart disease in a North Dakota community. Fournal of the American Medical Association, 172, 1261.

Registrar-General (1970). Decennial Supplement, England and Wales, I96r. Area Mortality Tables. H.M.S.O., London.

Rigal, R. D., Lovell, F. W., and Townsend, F. M. (1960). Pathologic findings in the cardiovascular systems of military flying personnel. American fournal of Cardiology, 6, 19.

Sievers, J. (1963). Myocardial infarction. Acta Medica Scandinavica, Suppl. 406.

Westlund, K., and Hougen, A. (1956). Myocardial infarction: an epidemiologic and prognostic study of patients from five departments of internal medicine in Oslo, 1935-1949. Acta Medica Scandinavica, Suppl. 315.

Westlund, K., and Hougen, A. (196I). Myocardial infarction among middle-aged Oslo males, 1956-57. Fournal of the Oslo City Hospitals, 11, 21.

Whitby, G. (1968). The enzyme response of the myocardium to ischaemia and infarction. In Acute Myocardial Infarction, p. 272. Ed. by D. G. Julian and M. F. Oliver. Livingstone, Edinburgh.

World Health Organization (1959). Hypertension and coronary heart disease: classification and criteria for epidemiological studies. World Health Organization. Technical Report Series, No. 168.

Requests for reprints to Dr. L. J. Kinlen, Department of the Regius Professor of Medicine, Radcliffe Infirmary, Oxford OX2 6HE. 